\title{
Clare Gerada: Mandatory training needs a fundamental review
}

\author{
Clare Gerada GP partner
}

Hurley Group, London, UK

On a quiet Sunday afternoon, I decided to update my compulsory online safeguarding training. Confronted by photos of bruised children, tales of abuse, and parental drug taking, I could bear no more.

Who on earth thought that such training should be done in sterile cyberspace, without recourse to discussion between peers? The instructional impact of doing this online amounted to anti-education. What with fire training, manual handling, and the other dozen or so mandatory requirements, my schedule is filled with having to "learn" what others decide is important for me to know to practise safely as a doctor.

When I look more closely at the requirements I'm struck by how confused they are. To start with, the training is often described interchangeably as statutory and mandatory, yet these are different (the former required by law, the latter determined by the employing organisation).

And it's not at all clear who determines that the training is required. Is it the Care Quality Commission, trusts, royal colleges, the General Medical Council, or all? For example, the Care Quality Commission doesn't have a list of mandatory training but does inspect against a set of subjects, and trusts or practices can be marked down if not all staff complete the training. ${ }^{1}$ Is it for revalidation? The General Medical Council requires doctors to judge for themselves how best to keep up to date, whether evidence of training should be presented at appraisal (there's no requirement to do so, although many appraisers ask to see evidence), and how evidence of completion should be presented (for instance, as a log of training or a certificate). It's also hard to find out who sets the requirements and monitors their growth or effectiveness-or even whether there's consistency against different sectors of health and social care or whether learning done in one setting can be transferable to another.

\section{Tick box exercise}

The current suite of mandatory training has, in good faith, been deemed important by individuals or organisations. But, over time, it's become at best a chore, an expensive tick box exercise.
At worst, it contributes to the high levels of mental distress in our profession.

And, given the constraints on clinicians' time, there's little left for doctor determined learning needs, identified using well established education principles. This could lead to poor care.

Delivery of much of the training also runs counter to educational good practice. What's apparent from educationalists is that the best outcomes-in terms of behaviour change, educational impact, and improved patient care-are achieved through experiential, active learner, peer group learning. This is a long way from where we are now, with the current dominant focus on passive learners and prescriptive, mandatory learning. This mode of teaching, or rather training, involves the mechanical transfer of information from teacher to student. Some could argue for some merit in having practical and non-clinical training requirements (fire training, manual handling) done online in one's own time, although even here learning is better done with room for discourse.

Doctors are encouraged to reflect on their clinical practice. Yet the current system leaves little time for true reflection, instead having become a largely solitary activity more akin to rumination. Doctors are expected to write down their thoughts, feelings, and actions on an electronic portfolio, mapped against a set of criteria and their own personal development plan. This contrasts starkly with the way reflection was developed in medical education, as a dialogical activity and a process of discovery.

Furthermore, the events doctors are reflecting on are not necessarily those that matter. Important issues of clinical and ethical uncertainty that expose the doctor's vulnerability are less likely to be explored.

Peer group learning (including supervision) allows doctors to explore the uncertainties of their work and, importantly, the emotional impact of working so close to death, despair, and disability. It also allows for cases to become real and for true learning to occur. 
Given the importance of some of the areas covered in the statutory and mandatory training and the scarcity of time for learning, it's important to design a system that uses best evidence for learning. Given the lack of evidence for the current approach I'd suggest that the system of training requirements (including subjects, content, duration, and format) needs a fundamental review.
1 Sparrow N. Nigel's surgery 70: Mandatory training considerations in general practice. Care Quality Commission. 10 Aug 2017. https://www.cqc.org.uk/guidance-providers/gps/ nigels-surgery-70-mandatory-training-considerations-general-practice.

Published by the BMJ Publishing Group Limited. For permission to use (where not already granted under a licence) please go to http://group.bmj.com/group/rights-licensing/ permissions 